\title{
Principios del derecho ambiental en el Acuerdo de París sobre Cambio Climático ${ }^{* * * * * *}$
}

\section{Principles of environmental law in the Paris Agreement on Climate Change}

RESUMEN

Este artículo se concentra en el último instrumento jurídico del régimen internacional de cambio climático, el Acuerdo de París, y en los principios ambientales que recoge. Se contextualiza con ese fin el fenómeno climático, su régimen propio y el largo camino que se ha seguido en las negociaciones climáticas para arribar a este acuerdo ambiental de última generación; luego se abordan los siete principios identificados como relevantes en el Acuerdo, así como otros temas de interés, para derivar algunas consecuencias que pueden generarse a la luz de este nuevo instrumento multilateral que está en proceso de implementación.

PALABRAS CLAVE

Cambio climático, principios ambientales, régimen internacional, derecho del medio ambiente, adaptación al cambio climático.

\section{ABSTRACT}

This article focuses on the latest legal instrument of the international regime on Climate Change, the Paris Agreement and the environmental principles it

Doctora en Derecho y Ciencias Sociales de la Universidad Nacional de Córdoba y LLM in International Law por las universidades de Heidelberg y de Chile. Directora del Instituto de Investigación en Derecho de la Universidad Autónoma de Chile (Santiago de Chile, Chile). Contacto: andrea.lucas@uautonoma.cly andrealucasg@hotmail.com

ORCID ID: 0000-0003-4371-7418.

** Recibido el 21 de febrero de 2018, aprobado el 11 de junio de 2019.

Para citar el artículo: LuCAS GaRín, A. Principios del derecho ambiental en el Acuerdo de París sobre Cambio Climático. En Revista Derecho del Estado, Universidad Externado de Colombia. N. ${ }^{\circ} 44$, septiembre-diciembre de 2019, pp. 195-226.

DOI: https://doi.org/10.18601/01229893.n44.08

*** Parte de estas reflexiones fueron expuestas en la Academia Nacional de Derecho de Córdoba el 20 de septiembre de 2017. La autora agradece los comentarios de los evaluadores anónimos. 
contains, for which the climate phenomenon, its own regime and the long path that has been followed in the climate negotiations will be contextualized, in order to arrive at this last generation environmental agreement; then the seven Principles identified as relevant in the Agreement and other topics of interest are addressed, to derive some consequences that may be generated in light of this new multilateral instrument that is in the process of implementation.

\section{KEYWORDS}

Climate Change, Environmental Principles, International Regime, Environmental Law, Adaptation to Climate Change.

\section{SUMARIO}

Introducción. 1. Marco teórico y metodología. 2. Contextualización del cambio climático, el régimen internacional y las negociaciones climáticas. 2.1. Primera etapa: los primeros pasos (1988-1994). 2.2. Segunda etapa: la difícil entrada en vigencia del Protocolo de Kioto (1994-2005). 2.3. Tercera etapa: las (intensas) negociaciones post-Kioto (2005-2015). 2.4. Cuarta etapa: un nuevo comienzo con el Acuerdo de París (de 2015 hasta la fecha). 3. Los principios ambientales del Acuerdo de París. 3.1. El principio de responsabilidades comunes pero diferenciadas. 3.2. El principio de desarrollo sostenible. 3.3 El principio de equidad. 3.4. El principio de transparencia. 3.5. El principio de buena gobernanza. 3.6. El principio de cooperación. 3.7. El principio precautorio. 4. Otros temas destacables del Acuerdo de París. Conclusiones. Referencias.

\section{INTRODUCCIÓN}

El cambio climático se presenta como un fenómeno científico que implica desafíos del orden económico, político, médico, arquitectónico, social y jurídico, entre otras áreas que se ven obligadas hoy a enfrentarlo ante la evidencia de sus consecuencias para las sociedades. Es lo que Rittel y Webber ${ }^{1}$ describieron como un "wicked problem" o problema retorcido, en un célebre trabajo de 1973, temas de políticas públicas pero que, por su propia naturaleza, tienen características difíciles de formular, que pueden ser descritas de manera diversa según quien lo aborda, lo que hace que el cambio climático se presente como tramposo y resulte casi imposible fijar sus alcances y consecuencias. 
El el plano del derecho internacional, la comunidad global ha ido asumiendo la problemática de un modo gradual desde fines de los años ochenta, en un proceso que ha conducido a la conformación del régimen internacional de cambio climático, al amparo de tres instrumentos convencionales que cuentan con un gran nivel de adhesión de los Estados, y que ha seguido evolucionando aun cuando se han producido altos en las negociaciones a nivel multilateral en varias ocasiones.

El efecto estabilizador de los asuntos mundiales que el derecho internacional conlleva se fortalece cuando los Estados manifiestan su consentimiento a través de tratados internacionales. En el caso del calentamiento global, el régimen climático está conformado por la Convención Marco de la ONU sobre Cambio Climático, que significó el puntapié inicial en 1992, que continuó con un problematizado Protocolo de Kioto, y que recientemente se ha visto fortalecido con el Acuerdo de París vigente desde el 4 de noviembre de 2016.

El Acuerdo de París se erige como el primer gran acuerdo ambiental multilateral del siglo XXI, cuya veloz entrada en vigencia renueva las esperanzas en la comunidad internacional y sus esfuerzos para enfrentar el cambio climático.

Este trabajo se concentra en el Acuerdo de París y en los principios ambientales que recoge, en nuestra opinión, razón por la cual sobrevolamos el cambio climático para pasar a contextualizar el régimen internacional y el camino que se ha seguido en las negociaciones hasta arribar al Acuerdo de París, distinguiendo cuatro etapas que se explican en el punto siguiente (1); luego se abordan los siete principios identificados por nosotros como relevantes en el Acuerdo (2), así como otros temas de interés (3), derivando conclusiones finales de algunas consecuencias que pueden generarse a la luz de este nuevo instrumento multilateral que se halla en pleno proceso de implementación. En el próximo punto se exponen el marco teórico y la metodología empleada.

\section{MARCO TEÓRICO Y METODOLOGÍA}

El presente artículo se enmarca en el derecho internacional ambiental y, en especial, en el régimen internacional de cambio climático; con más de un cuarto de siglo de vigencia, este último, hoy, se presenta como un ámbito donde la implementación es la clave del futuro.

Para contextualizar el régimen internacional dividimos su proceso de conformación en las siguientes etapas: 1) Primera etapa: los primeros pasos (1988-1994); 2) Segunda etapa: la difícil entrada en vigencia del Protocolo de Kioto (1994-2005); 3) Tercera etapa: las (intensas) negociaciones postKioto (2005-2015); 4) Cuarta etapa: un nuevo comienzo con el Acuerdo de París (2015 hasta la fecha). Cada una de las etapas es abordada en el acápite siguiente. 
La etapa actual del régimen climático presenta algunos puntos sobresalientes: la actuación doméstica adquiere máxima relevancia, ya no se trata de que el derecho internacional ambiental, desde afuera, quiera imponer a los Estados límites a la emisión de gases de efecto invernadero, sino que son los propios Estados quienes deben determinar sus niveles de emisión y la manera de respetarlos; se acaba la distinción entre países desarrollados y países en desarrollo en cuanto a los compromisos; la transferencia de tecnología y el financiamiento adquieren mayor relevancia; para el período que viene, que se concibe como de largo plazo, hay una apuesta por una cooperación más constructiva, con una acción mancomunada frente al cambio climático ${ }^{2}$.

Así las cosas, la exploración de los principios que deben delinear esta etapa de implementación se puede entender como un aporte concreto de cara a los desafíos que el régimen climático supondrá para los Estados a nivel doméstico, y que se presentarán en el mismo régimen internacional. La implementación, sin duda, tendrá un carácter técnico pero también jurídico, y la lectura que proponemos desde el Acuerdo de París debe guiar a los operadores políticos, jurídicos, científicos, etc.

Coincidimos con Rüdiger Wolfrum ${ }^{3}$ en que el término "principios" pueden significar una de dos cosas: o referirse a principios meta-legales, es decir, principios generados dentro de un discurso filosófico o ético y luego introducidos en un sistema normativo, o referirse a principios inherentes o desarrollados desde un cuerpo particular de normas o un régimen general; es en este último sentido que tomaremos el término. Nos concentraremos en los principios desarrollados por el derecho internacional ambiental en un versión amplia que pensamos ha informado el Acuerdo de París ${ }^{4}$. Esta decisión obedece a que consideramos que estos principios deben ser guías de interpretación en las tareas de implementación del Acuerdo tanto para los Estados como para la propia institucionalidad creada por el Acuerdo, adquiriendo con ello utilidad frente a un régimen marco en constante evolución.

En cuanto al marco metodológico de esta investigación, se analizará el régimen climático internacional, que como ya dijimos se ubica dentro del derecho internacional ambiental, y en particular, el Acuerdo de París. La metodología de investigación será de tipo descriptivo, en orden a presentar los textos legales atinentes, y luego asumirá un carácter exploratorio para, a

2 Cosmin Corendea concluye que el Mandato de París tiene una perspectiva centrada en el hombre que es esencial para enfrentar el cambio climático. Véase CoRENDEA, C. Hybrid legal approaches towards climate change: Concepts, mechanisms and implementation. En Annual Survey of Int'l \& Comp. Law. 21, 2016, 29-41.

3 Véase Wolfrum, R. Sources of International Law. En The Max Planck Encyclopedia of Public International Law. Oxford: Oxford University Press, 2012, párr. 33.

4 Concordamos con la terminología empleada por Miren Sarasíbar Iriarte, quien habla de "principios informadores de la Convención". Véase Régimen jurídico del cambio climático. España: Lex Nova, 2006, 87 ss. 
partir de observaciones generales sobre los alcances de los principios, poder realizar aportes para la cuarta etapa del régimen que hemos mencionado.

Las fuentes empleadas son principalmente bibliográficas y documentales, como las siguientes: tratados internacionales, doctrina especializada, documentos de organismos públicos (nacionales e internacionales) y revistas científicas.

\section{LA CONTEXTUALIZACIÓN DEL CAMBIO CLIMÁTICO, EL RÉGIMEN INTERNACIONAL Y LAS NEGOCIACIONES CLIMÁTICAS}

El cambio climático, como un desafío ambiental a largo plazo, ha significado el surgimiento de un régimen legal internacional como el marco jurídico donde los Estados encuadran sus acciones para enfrentar esta problemática con el fin último de aumentar la resiliencia de sus poblaciones.

Todo surge a partir de las emisiones de gases de efecto invernadero (GEI). Los mismos han estado presentes en la atmósfera desde siempre, pero su aumento en las últimas décadas ha conducido a que la atención se haya focalizado en el clima. La atmósfera permite la vida en la tierra y contiene los GEI que retienen parte de la energía del sol, nuestra principal fuente de energía. Como se ha dicho por la doctrina especializada, "si toda la energía absorbida del sol fuera reflejada al espacio, la temperatura media del aire en la superficie de la tierra sería de $-19^{\circ} \mathrm{C} "{ }^{\prime}$.

Este es un proceso natural que desde la era industrial se ha visto incrementado por la emisión de estos gases, los que de manera natural conforman de manera minoritaria la atmósfera; aquí se destaca el dióxido de carbono $\left(\mathrm{CO}_{2}\right)$, gas que se genera a partir de la combustión y que tiene un elevado tiempo de residencia en la atmósfera ya que no se descompone sino que solo desaparece por mecanismos biológicos o geológicos que constituyen parte del "ciclo del carbono" ". Este GEI está acompañado por el metano $\left(\mathrm{CH}_{4}\right)$, el óxido nitroso $\left(\mathrm{N}_{2} \mathrm{O}\right)$, el hexafluoruro de azufre $\left(\mathrm{SF}_{6}\right)$, el hidrofluorocarbono (HFC) y el perfluorocarbono ( $\mathrm{PFC}$ ), entre otros. El aumento en la concentración de estos gases hace que absorban más energía y, por ende, se incrementa la temperatura.

Por su parte, el sistema climático se puede definir como un sistema complejo e interactivo que está conformado por el espacio exterior, la litosfera, la criosfera, la biosfera, la hidrosfera y la atmósfera. El clima surge del equilibrio que se produce en el intercambio de energía, masa y movimiento de esos componentes, siendo la atmósfera quien tiene el rol de estabilizar

5 Cfr. Robador Moreno,A. Cambios climáticos, Madrid: Los libros de la catarata, 2015, 32.

6 Ibíd., 32 ss. Por esto el cambio climático también es un tema de las generaciones futuras. 
la temperatura en el planeta y permitir la vida en todas sus manifestaciones en la tierra ${ }^{7}$.

El cambio climático se refiere a un cambio en las estadísticas de la atmósfera durante décadas ${ }^{8}$. El aumento de la temperatura es la principal evidencia del fenómeno climático, pero no es la única; entre las más relevantes tenemos el aumento del nivel del mar, el aumento de las precipitaciones, la pérdida de la masa de la capa de hielos (tanto de Groenlandia como de la Antártida), y eventos extremos severos como inundaciones, sequías, huracanes y olas de calor.

Estas evidencias físicas llevaron a que se movilizara la comunidad internacional, dando lugar al régimen climático que Borràs Pentinat describe como un régimen para el derecho internacional porque "hace referencia a un tratado internacional, a un interés común y compartido por las Partes y a una regulación válida para todas ellas, así como a un mecanismo institucional para la promoción de los objetivos del tratado en un sector de regulación jurídica determinado"9.

Veremos la manera en que se fue conformando el régimen internacional con base en las cuatro etapas señaladas más arriba.

\subsection{Primera etapa: los primeros pasos (1988-1994)}

El órgano internacional que ha brindado información científica sobre el fenómeno es el Grupo Intergubernamental de Expertos sobre el Cambio Climático (IPCC) ${ }^{10}$, que ha confirmado la influencia humana en el sistema climático y los impactos generalizados en los sistemas humanos y naturales.

Con las informaciones del Primer Reporte del IPCC en 1990, se inició el proceso de negociación intergubernamental en el ámbito de las Naciones Unidas, mediante la decisión de la Asamblea General de preparar una convención

7 Seguimos a Drnas de Clément, Z. Cambio climático: algunas consideraciones de carácter introductorio. En Drnas de Clément, Zlata (dir.). Cuaderno de Derecho Ambiental, Número 1, Cambio Climático. Córdoba: Academia Nacional de Derecho y Ciencias Sociales de Córdoba, 2009, 10.

8 Casola y Freier explican: "En términos simples, el cambio climático es una consecuencia del aumento de la temperatura del medio ambiente terrestre, lo cual provoca consecuencias adversas tales como el derretimiento de glaciares, el aumento del nivel del mar, sequías y la extinción de flora y fauna". CASOLA, L. y FreIER, A. El nexo entre cambio climático y energía renovable en el Mercosur. Un análisis comparativo de las legislaciones de Argentina y Brasil. En Revista Derecho del Estado, Universidad Externado de Colombia. N. ${ }^{\circ}$ 40, 2018, 153-179, 155.

9 Borràs Pentinat, S. Los regímenes internacionales de protección del medio ambiente. Valencia: Tirant lo Blanch, 2011, 18.

10 Grupo Intergubernamental de Expertos sobre el Cambio Climático. Cambio Climático. Informe de Síntesis 2014. Suiza: IPCC y Organización Meteorológica Mundial (OMM), 2015, 2. 
general eficaz sobre los cambios climáticos que contenga los compromisos apropiados y los instrumentos conexos ${ }^{11}$.

Con esta preocupación y voluntad de los Estados se arribó a la Conferencia de las Naciones Unidas sobre el Medio Ambiente y el Desarrollo, gran encuentro internacional llevado a cabo en 1992 en Río de Janeiro (Brasil), en el que se adoptó el texto de la Convención Marco sobre Cambio Climático (en adelante, CMNUCC) ${ }^{12}$, que entró en vigor en 1994. Actualmente, 197 Estados han adherido a la Convención Marco, lo que representa un resultado ciertamente exitoso.

Podríamos afirmar que una de las claves del éxito del régimen internacional ha sido poder nutrirse y actualizarse cada cierto tiempo (el IPCC ha emitido cinco reportes) con estas informaciones científicas que, como es sabido, deben estar presentes en toda medida ambiental. Su conformación también es una de las razones de su credibilidad, pues más de 2.000 científicos de distintas áreas, pertenecientes a cinco regiones del mundo, son propuestos por los gobiernos, y junto a las reuniones específicas, se mantienen encuentros abiertos con la sociedad civil de manera periódica.

De acuerdo con Dessler, el "Resumen para Responsables de Políticas" que acompaña cada reporte presenta de manera sintética y amigable cada informe y se redacta en un encuentro final, una vez que el reporte total ha sido redactado; cada uno de los representantes de los gobiernos revisa el resumen, asegurando que tenga la suficiente amplitud para que todos estén de acuerdo, y si hubiera disenso en alguna oración, se coloca una nota al pie de página que lo consigne ${ }^{13}$.

\subsection{Segunda etapa: la difícil entrada en vigencia del Protocolo de Kioto (1994 a 2005)}

Una vez iniciada la vigencia de la Convención Marco, las Partes se abocaron a la negociación de un protocolo que fijara la "letra chica" en relación con los compromisos de los Estados, en especial de los países desarrollados. Esto derivó en el segundo instrumento del régimen internacional, el Protocolo de Kioto, con una entrada en vigencia difícil dado que, si bien fue adoptado en

11 A/RES/45/212 del 21 de diciembre de 1990, titulada "Protección del clima mundial para las generaciones presentes y futuras". 71. . sesión plenaria.

12 La Convención define al cambio climático así: "2. Por 'cambio climático' se entiende un cambio de clima atribuido directa o indirectamente a la actividad humana que altera la composición de la atmósfera mundial y que se suma a la variabilidad natural del clima observada durante períodos de tiempo comparables" (art. 1 num. 2).

13 DessLer, A. Introduction to Modern Climate Change, 2. ${ }^{\text {a }}$ ed. UK:, Cambridge University Press, 2016, 9 y 10. 
1997, solo entró en vigor en febrero de 2005, luego de un largo proceso de ratificación ${ }^{14}$.

Del Protocolo de Kioto deben realzarse dos puntos: el primero es que los países desarrollados asumen compromisos cuantificados de limitación y reducción de las emisiones para el período 2008-2012 (extendido hasta el 2020), de manera que no hay obligaciones legales para los países en desarrollo, contando con un tratamiento diferenciado a su favor; el segundo punto tiene que ver con que se añaden herramientas para abaratar los costos de mitigación, creando tres mecanismos de mercado para intercambiar créditos de carbono, los llamados mecanismos flexibles, a saber: Aplicación Conjunta (AC), Mecanismo de Desarrollo Limpio (MDL, especialmente importante para los países en desarrollo ${ }^{15}$ ) y el Comercio de Emisiones de Carbono.

\subsection{Tercera etapa: las (intensas) negociaciones post-Kioto (2005-2015)}

Inmediatamente después de la entrada en vigor del Protocolo de Kioto, los Estados Parte se concentraron en las negociaciones climáticas para reemplazar el Protocolo, dado que el sistema enfrentaba el gran desafío de alcanzar un acuerdo internacional que avanzara en los compromisos; en el entretiempo se fueron adoptando distintas decisiones que fueron implementando el Protocolo de Kioto $^{16}$.

Las negociaciones climáticas lograron su cometido en la Conferencia de las Partes de la Convención Marco de las Naciones Unidas sobre el Cambio Climático de 2015 (COP 21) en París. El proceso de negociaciones multilaterales se ha extendido por más de dos décadas, y cada año las Partes se han reunido para dar un paso más en el régimen climático; las posiciones de las Partes han ido cambiando, y la base científica sobre la que se han ido tomando las decisiones a menudo ha sido puesta en duda. Muchas partes han estado negociando al mismo tiempo, con las urgencias que las evidencias del cambio climático han ido generando en los propios Estados (pensemos en los Estados insulares, por dar solo un ejemplo).

El Acuerdo de París concilia en un texto todos los compromisos que se fueron alcanzando en la última década de negociaciones; destacamos dos elementos del Acuerdo: respecto de la temperatura, se encaminan los esfuerzos

14 El Protocolo de Kioto requería de 55 Estados Partes (incluidos Estados del Anexo 1) cuyas emisiones de GEI equivalieran al $55 \%$ del total de emisiones de $\mathrm{CO}_{2}$ de los países desarrollados en 1990. Similar fórmula requirió el Acuerdo de París por el artículo 21.

15 De los tres mecanismos y en un contexto post-Acuerdo de París, es de prever que los mercados de emisiones sigan existiendo y de hecho se intensifique su utilización por los Estados. Lo que no está claro es qué ocurrirá con el Mecanismo de Desarrollo Limpio (MDL) posterior a 2020.

16 Como los Acuerdos de Marrakech, Decisión 15/CP.7 de la Conferencia de las Partes, que operativizó los mecanismos previstos en los artículos 6,12 y 17 del Protocolo de Kioto (en la Séptima Conferencia de las Partes celebrada en Marruecos, en 2001). 
para limitar el aumento de la temperatura con preferencia a los 1,5 grados centígrados y por debajo de $\operatorname{los} 2{ }^{\circ} \mathrm{C}$ a niveles preindustriales; respecto de los compromisos, se incluye un mecanismo jurídico, las contribuciones previstas y determinadas a nivel nacional (NDC), que presentarán todos los Estados y que describirá medidas más intensas y ambiciosas adoptadas en el marco de las obligaciones anteriores fijadas por esa Parte.

\subsection{Cuarta etapa: un nuevo comienzo con el Acuerdo de París (de 2015 hasta la fecha)}

El Acuerdo de París es el convenio multilateral ambiental más exitoso en cuanto a su entrada en vigor, la que ha sucedido en tiempo récord, poco más de cinco meses, alcanzándose el mínimo de adhesiones para asegurar su vigencia el 4 de noviembre de 2016; ya está funcionando y ha habido tres períodos de sesiones de la Conferencia de las Partes en Marrakech (2016), Bonn (2017) y Katowice (2018) ${ }^{17}$.

La retirada de Estados Unidos del Acuerdo significó un golpe para la agenda de cambio climático, y se produjo en razón de una decisión del presidente Trump que modificó la ratificación realizada por el presidente Obama en septiembre 2016, aun cuando el nombre de "Acuerdo" fue decidido precisamente para sortear los obstáculos que se podían presentar si se llamaba "Protocolo", pues podía comportar su sometimiento al Congreso de Estados Unidos para su aprobación ${ }^{18}$. Además, en la redacción del Acuerdo hubo mucho cuidado de la delegación norteamericana en evitar las disposiciones jurídicamente vinculantes que pudieran generar la necesidad de aprobación legislativa ${ }^{19}$.

17 El 5 de octubre de 2016 el Secretario General de las Naciones Unidas anunció que ese día se cumplían las condiciones para la entrada en vigor del Acuerdo de París y que el mismo entraría en vigor el 4 de noviembre de 2016. Actualmente 184 Estados lo han ratificado. Véase: https://unfccc.int/process/the-paris-agreement/status-of-ratification [Consultado el 16 de febrero de 2019]. La COP 252019 se realizará en Chile.

18 Considérese, respecto de la renuncia de alguna de las Partes, cuanto señala el Acuerdo en el artículo 28: "1. Cualquiera de las Partes podrá denunciar el presente Acuerdo mediante notificación por escrito al Depositario en cualquier momento después de que hayan transcurrido tres años a partir de la fecha de entrada en vigor del Acuerdo para esa Parte. 2. La denuncia surtirá efecto al cabo de un año contado desde la fecha en que el Depositario haya recibido la notificación correspondiente o, posteriormente, en la fecha que se indique en la notificación". Estados Unidos notificó formalmente a las Naciones Unidas su denuncia del Acuerdo el 4 de agosto de 2017. Véase: https://www.efe.com/efe/usa/sociedad/eeuu-notifica-a-la-onu-su-retiradadel-acuerdo-de-paris-sobre-el-clima/50000101-3344848 [Consultado el 9 de febrero de 2019]. La postura errática de Estados Unidos frente al régimen internacional no es nueva para el régimen de cambio climático.

19 Jorge E. Viñuales explica que la ratificación del Acuerdo por Estados Unidos y China, el 3 de septiembre de 2016, fue un gran momento para asegurar su entrada en vigencia, y para superar el argumento de quienes sostenían que los grandes emisores no ratificaban estos tratados, lo que proporcionaba una excusa para la inacción. Viñuales, J. E. The Paris Agreement on Climate Change: Less is more. En German Yearbook of International Law. 2017, 21. 
En cuanto a la estructura formal del Acuerdo de París, cuenta con un Preámbulo y 29 artículos, y es el anexo de una decisión de la cop (Proyecto de decisión -/CP.21) que la integra y brinda algunas guías para su realización. El Preámbulo se refiere a una cantidad de temas muy interesantes entre los que destaca la seguridad alimentaria ${ }^{20}$, como parte de los grandes objetivos del régimen internacional, que se actualizan ${ }^{21}$, y que exige que las políticas climáticas y las políticas agrícolas sean cuidadosamente alineadas para prevenir los efectos secundarios negativos de la mitigación del cambio climático en la seguridad alimentaria y viceversa ${ }^{22}$.

La finalidad del Acuerdo es indicada en el artículo 2: "mejorar la aplicación de la Convención"; así nos deriva a la Convención Marco que apunta a la estabilización de las concentraciones de gases de efecto invernadero en la atmósfera a un nivel que prevenga los peligros derivados de las interferencias antropógenas en el sistema climático (art. 2 CMNUCC). Lo anterior denota que esta finalidad es a largo plazo, de allí este marco jurídico que sigue en proceso de construcción.

\section{LOS PRINCIPIOS AMBIENTALES DEL ACUERDO DE PARÍS}

Mencionamos arriba los dos instrumentos previos que conforman el régimen internacional de cambio climático, a saber, la Convención Marco y el Protocolo de Kioto. Destacan en la Convención su Preámbulo y el artículo 3, y estos principios son retomados en el Acuerdo de París, desperdigados en el texto y también ampliados y actualizados, como veremos.

El derecho internacional ambiental, como una rama joven del derecho internacional pero de rápida evolución, ha ido desarrollando principios específicos cuyo carácter, además de la propia autonomía de esta rama del derecho internacional, despierta alguna controversia, la que no se abordará en esta oportunidad $^{23}$. Sobre el estatus de estos principios se ha señalado que algunos forman parte de la "costumbre internacional", mientras que otros todavía están en un proceso de consolidación; por esa razón, en este trabajo no nos

20 Además, el Preámbulo contiene una referencia al "desarrollo sostenible y la erradicación de la pobreza", y prontamente expresa: "Teniendo presentes la prioridad fundamental de salvaguardar la seguridad alimentaria y acabar con el hambre, y la particular vulnerabilidad de los sistemas de producción de alimentos a los efectos adversos del cambio climático...".

21 El artículo 2 de la Convención Marco fija el objetivo y agrega: "que la producción de alimentos no se vea amenazada y permitir que el desarrollo económico prosiga de manera sostenible".

22 Véase Jonathan Verschunren. The Paris Agreement on Climate Change: Agriculture and food security. En Eur. J. Risk Reg. Vol. 7, 54, 2016, 54-57, 54.

23 Véase Drnas de ClÉMENT, Z. Fuentes del derecho internacional del medio ambiente. En Síndico, F. (coord.), Environmental Law. Londres: University of Surrey y CMP Publishers, 2010. Véase también DRNAS DE CLíEMENT, Z. Principios generales del derecho internacional ambiental como fuente normativa. El principio de precaución. En Anuario, Centro de Investigaciones Jurídicas y Sociales de la Universidad Nacional de Córdoba, IX. 2006, 245-265. 
detendremos en el estatus, y preferiremos considerarlos del modo más práctico posible ${ }^{24-25}$. En el futuro y en posteriores estudios confiamos que podrán ir configurando su relevancia como fuente del derecho internacional ambiental ${ }^{26}$.

La ardua tarea de implementación que está emprendiendo el sistema requiere tener pistas de cómo interpretar el Acuerdo de París, y estas líneas podrán ayudar en ello tanto a la propia institucionalidad de la Convención Marco como a los Estados parte activa de la comunidad.

La mayoría de estos principios están recopilados en la Declaración de Río sobre el Medio Ambiente y el Desarrollo ${ }^{27}$, mientras que otros son más novedosos y se hallan en plena evolución; nos detendremos en siete principios que entendemos están presentes en el Acuerdo de París, a saber: el principio de responsabilidades comunes pero diferenciadas, el principio de desarrollo sostenible, el principio de equidad, el principio de transparencia, el principio de buena gobernanza, el principio de cooperación y el principio precautorio. A continuación analizaremos cada uno de ellos.

\subsection{El principio de responsabilidades comunes pero diferenciadas ${ }^{28}$}

Este principio ha estado en el corazón de las negociaciones del cambio climático desde la concepción del régimen internacional; al inicio tenía que

24 Algunos de los problemas que se generan ante las fuentes del derecho internacional en general, son expuestos por Jean d'Aspremont, quien plantea las teorías de las fuentes desde la perspectiva basada en los sujetos que se ha movido hacia un sistema de reglas, pasando por los que se basan en la validez sustantiva y los que sostienen teorías más dinámicas desde lo social. Véase d'Aspremont, J. Towards a new theory of sources in International Law. En ORFORD, A. y Hoffmann, F. (eds.), The Oxford Handbook of the Theory of International Law. United States of America: Oxford University Press, 2016, 546-559.

25 Para descubrir la existencia de principios ambientales, Hernán Valencia Restrepo propone tres vías: "la legal, la jurisprudencial y la doctrinal". Véase Valencia RestrePo, H. "Introducción a una nomoárquica ambiental", en DRnAS DE ClÉMENT, Z. (coord.), Estudios de derecho internacional en homenaje al profesor J. Ernesto Rey Caro. T. 1. Córdoba: Marcos Lerner, 2002, 129.

26 Como ejemplo de esta discusión citamos a Simone Schiele, quien opina que los principios del régimen climático que están previstos en el Preámbulo de la Convención Marco deben interpretarse como guías para la acción colectiva pero que los principios incluidos en el artículo 3 de la CMNUCC son obligatorios legalmente. SCHIELE, S. Evolution of International Environmental Regimes. The Case of Climate Change. UK: Cambridge University Press, 2014, 224.

27 Naciones Unidas. Declaración de Río sobre el Medio Ambiente y el Desarrollo. Disponible en: http://www.un.org/spanish/esa/sustdev/agenda21/riodeclaration.htm [Consultado el 9 de febrero de 2019].

28 Principio 7 de la Declaración de Río de 1992: "Los Estados deberán cooperar con espíritu de solidaridad mundial para conservar, proteger y restablecer la salud y la integridad del ecosistema de la Tierra. En vista de que han contribuido en distinta medida a la degradación del medio ambiente mundial, los Estados tienen responsabilidades comunes pero diferenciadas. Los países desarrollados reconocen la responsabilidad que les cabe en la búsqueda internacional del desarrollo sostenible, en vista de las presiones que sus sociedades ejercen en el medio ambiente mundial y de las tecnologías y los recursos financieros de que disponen". 
ver con la responsabilidad de los países desarrollados que han explotado el planeta desde la Revolución Industrial, y que son los que han emitido gran parte de los gases que están en la atmósfera, si se los compara con los países en desarrollo, los cuales llegaron más tarde a la industrialización ${ }^{29}$.

En el Acuerdo expresa en el artículo 2 numeral 2 que "[e]l presente Acuerdo se aplicará de modo que refleje la equidad y el principio de las responsabilidades comunes pero diferenciadas y las capacidades respectivas, a la luz de las diferentes circunstancias nacionales". El concepto de responsabilidades comunes pero diferenciadas implica la persecución de un objetivo común, y que los Estados asuman diferentes obligaciones, dependiendo de su situación socio-económica y/o de sus contribuciones históricas al problema ambiental.

El resultado de las responsabilidades comunes es que todos los Estados, de los países desarrollados como de los países en desarrollo, deben participar en la formación e implementación de las medidas para hacer frente al cambio climático. Tradicionalmente era en la aplicación que surgían las diferencias, siendo las principales que los derechos y obligaciones son sustancialmente diferentes, y que la aplicación de las provisiones sustantivas ocurre en tiempos diferenciados. La máxima expresión de este principio se logró en el Protocolo de Kioto, que empleó el mecanismo de obligar solo a los países desarrollados con compromisos cuantificados de limitación y reducción de las emisiones de GEI.

Desde una visión fundamental, el término "común" expresa solidaridad en la protección del medio ambiente e implica compartir las obligaciones de una manera que refleje equidad. Como explica Hestermeyer, la conservación es un objetivo común para los Estados, por lo que se involucran directamente (en este caso en la conservación del clima), siendo la cooperación un caso de solidaridad "self-centred" 30 .

El elemento base es el de la integralidad de la tierra y el consecuente reconocimiento de la responsabilidad global en su cuidado, cuestión de interés de toda la humanidad y no un tema de jurisdicción particular de cada Estado. Se ha indicado que hay una conexión posible entre este principio y el principio de preocupación universal o de "common concern"31, que comparten la

29 En palabras de Arístegui: "Este reconocimiento de responsabilidad histórica no implicó ninguna forma de 'indemnización' hacia los países más pobres, pero sí el compromiso jurídicamente vinculante de asumir en adelante obligaciones de mitigación y de cooperación internacional en la materia". ARÍsteguI, J. P. Evolución del principio "Responsabilidades comunes pero diferenciadas" en el régimen internacional del cambio climático. En Anuario de Derecho Público. 2012, 585-611, 586.

30 Hestermeyer, H. Reality or Aspiration? Solidarity in International Environmental and World Trade Law. En H. Hestermeyer et al. (eds.), Coexistence, Cooperation and Solidarity: Liber Amicorum Rüdiger Wolfrum. Vol. 1. Martinus Nijhoff, 2012, 45-63, 54.

31 Seguimos el trabajo de Cottier, T.; Aerni, P.; Karapinar, B.; Matteotti, S.; De SéPibus, J. y ShIngal, A. The Principle of Common Concern and Climate Change. En Archiv des Völkerrechts. Vol. 52, 2014, 293-324, 307 ss. 
idea de una responsabilidad compartida por una preocupación compartida. Desde el principio de responsabilidades comunes pero diferenciadas es posible identificar respuestas y soluciones, en la medida en que el principio de common concern está en un proceso de desarrollo en el derecho internacional.

Reflexionando sobre la relación entre el principio de responsabilidades comunes pero diferenciadas y el principio de no hacer daño a otro Estado, Mayer ${ }^{32}$ explica que este último es rara vez tenido como parte de las respuestas al cambio climático, y que justamente el principio de no hacer daño a otro Estado ha sido reemplazado por el principio de responsabilidades comunes pero diferenciadas en el régimen internacional de cambio climático.

Esto resulta extraño porque desde la Declaración de Estocolmo sobre el Medio Ambiente Humano de $1972^{[33]}$ el principio 21 es importante y está implícito en todo régimen ambiental que se desarrolla, asegurando la responsabilidad del Estado por los daños ambientales sufridos por otro Estado o fuera de las áreas de su jurisdicción nacional, así como que los Estados no pueden causar daños fuera de su territorio ${ }^{34}$. Se deriva de esto que la estrategia de los países desarrollados e industrializados ha sido la de evitar toda discusión sobre el principio de no daño, desde los inicios de las negociaciones climáticas, es decir, por 25 años ${ }^{35}$.

Este olvido u omisión del principio de no hacer daño en el régimen internacional tiene implicaciones específicas en el marco del sistema climático en atención a que, en especial ante el Acuerdo de París, podríamos enfrentarnos a un régimen más fuerte que reconoce obligaciones y responsabilidades, y no solo a un régimen basado en la voluntariedad y en la asistencia, como lo definen algunos.

Mencionamos el nuevo mecanismo que trae el Acuerdo de París, y hablamos de las contribuciones determinadas a nivel nacional (NDC), que consisten en que los Estados deben presentar de manera voluntaria sus objetivos de

32 MAYER, B.The relevance of the No-Harm Principle to climate change law and politics. En Asia-Pacific Journal of Environmental Law. Vol. 19, 2016, 79-104, 80 ss.

33 Adoptada en la Conferencia de las Naciones Unidas sobre el Medio Ambiente Humano, 16 de junio de 1972 .

34 El contenido del principio se sintetiza en dos normas principales: la soberanía territorial de los Estados sobre su medioambiente (incluye la posibilidad de tomar diversas opciones sobre sus recursos naturales) y no causar daño a otro Estado. Los orígenes del principio se encuentran en el Tribunal Arbitral en el Asunto relativo a la Fundición de Trail (Trail Smelter Arbitration), cuyo holding señala que "ningún Estado tiene el derecho de usar o permitir el uso de su territorio en forma que el territorio de otro Estado o las personas o propiedades que allí se encuentran sufran daños". El principio 2 de la Declaración de Río de 1992 retoma este principio veinte años después.

35 Según Mayer, quien señala que los países desarrollados incluso bloquearon la posibilidad de que la Comisión de Derecho Internacional en 2011 y 2013 tratara el tema (se llegó a nominar un Informante sobre Protección de la Atmósfera). También han bloqueado a Palau y los Estados insulares que iniciaron una campaña para lograr que la Asamblea General de onU solicitara una opinión consultiva a la Corte Internacional de Justicia sobre cambio climático. Ob. cit., 84. 
reducción de emisiones GEI generales (con todos los sectores económicos e industriales incluidos), además de la indicación de las políticas orientadas a sectores específicos para alcanzarlos. Este instrumento, nacido en Varsovia ${ }^{36}$, obliga a los Estados a presentar cada cierta cantidad de años (cinco para los de nuestra región) sus objetivos de reducciones, y a que cada vez que las presentan, estas sean más profundas. Todo esto complementado por otras normas del Acuerdo que garantizan la transparencia y la rendición de cuentas.

Es destacable que se protege la flexibilidad de los Estados para elegir, dentro de las opciones de políticas y medidas públicas a adoptar para enfrentar el cambio climático, su espacio de toma de decisiones conforme a sus propias realidades.

Desde la perspectiva política, para septiembre de 2016, 187 Estados habían enviado sus contribuciones previstas y determinadas a nivel nacional al sistema, y 156 Estados habían enviado sus intenciones de someterse a reformas institucionales, según relata Cordonier ${ }^{37}$. Estas contribuciones nacionales serán consideradas como las primeras para cada Estado (salvo que envíe otras), y ya están incorporadas en el nuevo registro público provisional del Acuerdo de París ${ }^{38}$.

La nueva lectura que el Acuerdo de París realiza del principio de responsabilidades comunes pero diferenciadas ha permitido, por un lado, superar las limitaciones que el Protocolo de Kioto tuvo en cuanto a la cobertura, con la exclusión de los países en desarrollo; por otro lado, se reconoce que la lucha contra el cambio climático es un proceso a largo plazo, exigiendo de los Estados mayores compromisos, reflejados en políticas públicas y medidas adecuadas que permitan cumplir con las reducciones propuestas.

\subsection{El principio de desarrollo sostenible}

Desde sus orígenes este principio, incorporado en el Informe Brundtland de 1987 por encargo de la Asamblea General de las Naciones Unidas a la Comisión Mundial sobre Medio Ambiente y Desarrollo, titulado "Nuestro futuro común", ha sido incluido en muchísimos instrumentos internacionales no solo del área ambiental, sino también referidos al desarrollo, entre los que el Acuerdo de París no podía ser la excepción ${ }^{39}$.

36 Específicamente está fijada en la Decisión 1/CP.19, "Intensificación de los trabajos relativos a la Plataforma de Durban".

37 Cordonier SEgGer, M.-C. Advancing the Paris Agreement on Climate Change for Sustainable Development. En Cambridge J. Int'l \& Comp. L. Vol. 5, n. ${ }^{\circ}$ 2, 2016, 202-237, 206.

38 En mayo de 2016 se instaló el Registro Provisional de NDC. Véase: http://newsroom. unfccc.int/es/acuerdo-de-paris/entra-en-funcionamiento-el-registro-internacional-de-contribuciones-determinadas-a-nivel-nacional/ [Consultado el 12 de febrero de 2019].

39 "El informe Brundtland tiene como principio rector la idea de que desarrollo y medio ambiente no pueden concebirse de modo separado", explica Luciana Abreu. "Miradas del desa- 
Conforme explica Beyerlin, el desarrollo sostenible se caracteriza con un estrecho vínculo entre los objetivos políticos del desarrollo económico y social, por una parte, y, por otra, la protección del medio ambiente, la calificación de la protección ambiental como parte integral de cualquier medida de desarrollo, y viceversa, y la perspectiva a largo plazo de ambos objetivos de política, que es la responsabilidad intergeneracional de los Estados ${ }^{40}$.

El Acuerdo asegura que los aspectos sociales, económicos y ambientales sean considerados en igualdad de condiciones al abordarse el cambio climático, no en forma complementaria ni descoordinada. Asimismo, determina la aplicabilidad práctica del principio por parte de los Estados, que deberán, a través de su legislación, estándares y, en especial, de sus políticas nacionales, implementar el régimen a nivel local.

Para alcanzar el desarrollo sostenible el Acuerdo de París propone tres objetivos específicos y operacionales (art. 2 num. 1$)^{41}$ :

1) Impulsar los esfuerzos para limitar el aumento de la temperatura con preferencia a los 1,5 grados centígrados, y acuerdan mantener el aumento de la temperatura global por debajo de los $2{ }^{\circ} \mathrm{C}$.

2) Aumentar la capacidad de adaptación a los efectos adversos del cambio climático y lograr un desarrollo con bajas emisiones de GEI.

3) Situar los flujos financieros en un nivel compatible con una trayectoria que conduzca a un desarrollo resiliente al clima y con bajas emisiones de gases de efecto invernadero.

El primer objetivo implica un enorme desafío para los reguladores dado que el mantenimiento de la temperatura con preferencia a los $1,5^{\circ} \mathrm{C}$, y por debajo de los $2{ }^{\circ} \mathrm{C}$, se convierte, en virtud del Acuerdo de París, en un objetivo global. El objetivo de París de mantener el cambio de temperatura global por debajo de los $2{ }^{\circ} \mathrm{C}$ es una base psicológicamente potente contra la cual se pueden medir las fallas de las políticas futuras. Rowell y van Zeben ${ }^{42}$

rrollo sustentable", en González Acosta G. Derecho ambiental y desarrollo sustentable. Buenos Aires: Ediciones Jurídicas, 2015, 23-45, 35.

40 Cfr. Beyerlin, U. Sustainable Development. En Wolfrum, R. (ed.), Max Planck Encyclopedia of Public International Law. Oxford University Press, 2013. Disponible en: www. mpepil.com [Consultado el 16 de octubre de 2015].

41 Para Francesca Romanin Jacur, "[e]l Acuerdo de París establece tres objetivos principales de carácter general que tienen que ver con los compromisos adquiridos por los países", y menciona el artículo 2 numeral 1. Además, destaca que "[1] os progresos del acuerdo se basan esencialmente en alcanzar obligaciones procedimentales de comunicación periódica, de revisión y de evaluación del progreso de las iniciativas emprendidas por los países con referencia a la mitigación, la adaptación y el traslado de recursos y tecnologías". RoMANIN JACUR, F. El Acuerdo de París sobre cambio climático: un tratado con muchos matices. En Jiménez GuANIPA, H. y Tous Chimá, J. (eds.), Cambio climático, energía y derechos humanos: desafíos y perspectivas. Bogotá: Universidad del Norte y Fundación Heinrich Böll, 2017, 22-32, 25 y 23.

42 Seguimos a Rowell y van ZeBec. A new status quo? The Psychological Impact of the Paris Agreement on Climate Change. En Eur. J. Risk Reg. Vol. 7, 2016, 49-53, 50. El impacto psicológico del Acuerdo de París seguramente derivará en investigaciones en ciencias sociales. 
sostienen que ese objetivo global tiene un impacto psicológico importante puesto que la gente procura adaptar su conducta al status quo.

Esto tiene que ver con las percepciones, con que el cambio climático es percibido como un nuevo condicionante del riesgo, y con la manera como los Estados deben cumplir y dar seguimiento a las medidas a las que se comprometen. El impacto psicológico del nuevo status quo que el clima no calentará más de $1.5^{\circ} \mathrm{C}$, o como máximo $2^{\circ} \mathrm{C}$, tendrá efectos en la población que obligan a que los Estados efectivamente cumplan con este objetivo y dejen de lado normas meramente aspirativas. Asimismo, la preocupación por el cambio climático tendrá efectos sobre los consumidores y sus preferencias (p. ej., respecto de los productos con huella de carbono).

En relación con el segundo objetivo operacional, este relaciona la adaptación con el desarrollo sostenible, siendo interesante, al respecto, la opinión de los especialistas que indican que las medidas de adaptación que deben tomarse serán una oportunidad para profundizar en el desarrollo, ante la necesidad de ir incrementando las medidas como respuesta a los estímulos climáticos presentes o esperados y a sus efectos, para moderar el daño o explotar oportunidades beneficiosas ${ }^{43}$; esto desde esta concepción tradicional, específicamente en términos de adaptación, se dice que debiera avanzarse hacia medidas de adaptación transformacional, en especial desde la perspectiva de países en desarrollo.

De acuerdo con Fankhauser y $\mathrm{McDermott}^{44}$, las medidas de adaptación transformacional son aquellas que cumplen tres requisitos: a) son medidas de gran escala; b) contienen abordajes nuevos y el uso de instrumentos nuevos, y c) implican un cambio estructural de las actividades económicas y/o en la ubicación de las actividades económicas. Esta adaptación transformacional se da con fricciones, dependiendo su éxito no tanto de la política económica sino de las políticas de planificación del desarrollo, y en muchos casos implica relocalización y migraciones de industrias y de empleados, entre otras acciones. Para tomar de ejemplo un país en desarrollo como Chile, los planes de adaptación que se están implementando hasta ahora no incluyen este tipo de medidas ${ }^{45}$.

43 Según explican Robinson, N.; Xi, W.; Harmon, L. y Wegmueller, S. Dictionary of Environmental and Climate Change Law. UK: Edward Elgar, 2013, 3.

44 Véase Fankhauser; S. y McDermott, T. K. J. Climate-resilent development: An introduction. En FANKHAuser, S. y McDermott, T. (eds.), The Economics of Climate-Resilient Development. UK: Edward Elgar, 2016, 8.

45 Chile cuenta con el Plan Nacional de Adaptación al Cambio Climático, que incluye los planes sectoriales: a) el Plan de Adaptación del Sector Silvoagropecuario, aprobado en 2013 por el CMs, actualmente en ejecución; b) el Plan de Adaptación al Cambio Climático para Pesca y Acuicultura, aprobado en 2015 por el CMS, de igual forma, actualmente en ejecución; c) el Plan de Adaptación al Cambio Climático en Biodiversidad, aprobado en 2014 por el CMs, en ejecución, y d) el Plan de Adaptación al Cambio Climático del Sector Salud (que abarca el periodo 2016-2020). Hay otros planes en proceso de diagnóstico y redacción. 
En cuanto al objetivo tercero, vislumbramos que ínsita está la llamada "economía verde", que en un primer acercamiento se refiere a los tres pilares del desarrollo sostenible, de modo de conectar medio ambiente y economía para contribuir al bienestar humano y a la equidad social a través de la reducción de la pobreza. "En un sentido más estrecho, la economía verde también ha sido considerada como una herramienta para realizar el desarrollo sostenible", señala Ghering ${ }^{46}$, y agrega que el derecho puede apoyar el desarrollo sostenible, respecto de lo cual menciona las leyes marco que pueden dar apoyo a la economía verde siempre que provean una coherencia necesaria entre objetivos económicos, ambientales y sociales.

Otro tema de interés que surge de este último objetivo tiene que ver con los flujos financieros, es decir, con el financiamiento; el artículo 9 está dedicado al financiamiento y a la necesidad de movilizar recursos desde los países desarrollados a los países en desarrollo. Incorpora una categorización de países para distinguir entre países desarrollados, países en desarrollo, países menos adelantados y países insulares; resulta interesante esta categorización que tendrá efectos sobre los nuevos procedimientos que deben implementarse al amparo del Acuerdo. Se dispone, por otra parte, que el mecanismo financiero de la Convención Marco es también el mecanismo del Acuerdo de París ${ }^{47}$.

El financiamiento del cambio climático es la parte crítica tanto a nivel internacional como nacional. Contar con esta asistencia es imprescindible para los países en desarrollo y ya nadie discute que la implementación de este régimen ambiental es muy compleja, tanto que debe venir de la mano de la transferencia de recursos por los países desarrollados. Otro punto que también se necesita tiene que ver con la transferencia de tecnología para mejorar la resiliencia al cambio climático y reducir las emisiones de gases de efecto invernadero ${ }^{48}$. Y también la conveniencia de la asistencia técnica es contemplada en el Acuerdo dentro de las iniciativas de desarrollo sostenible que se generen. Estos pueden ser los puntos más difíciles de lograr para el Acuerdo.

46 GHeRING, M. La transición legal a una economía verde. En Revista de Derecho Ambiental. $\mathrm{IV}, \mathrm{n} .^{\circ} 6,2016,8-43,14$. El autor menciona que junto con las leyes hay una tendencia al uso de códigos voluntarios y medidas de buena gobernanza que pueden no tener fuerza legal pero que sí son relevantes desde la perspectiva de los consumidores. Ob. cit. 21. Posiblemente esta tendencia es común en países desarrollados.

47 El mecanismo de financiación (art. 11 CMNUCC) es el órgano que funciona bajo la dirección de la Conferencia de las Partes y que le rendirá cuentas a ella, teniendo a su cargo el suministro de recursos financieros (como subvenciones) para asegurar la transferencia de tecnología. La condición de funcionamiento que fija la Convención es que deberá tener una representación equitativa y equilibrada de todas las Partes, ratificando que la transparencia es el modo de desenvolvimiento de su actividad.

48 Artículo 10: "1. Las Partes comparten una visión a largo plazo sobre la importancia de hacer plenamente efectivos el desarrollo y la transferencia de tecnología para mejorar la resiliencia al cambio climático y reducir las emisiones de gases de efecto invernadero". 
Otra propuesta del Acuerdo de tipo operativo es que establece el mecanismo de desarrollo sostenible, para contribuir a la mitigación de las emisiones y apoyar el desarrollo sostenible, que funcionará bajo la autoridad y la orientación de la COP, y que podrá ser utilizado de manera voluntaria por las Partes ${ }^{49}$. Cordonier Segger explica al respecto: "El nuevo mecanismo podría recurrir a ciertas experiencia acumulada a través del Mecanismo de Desarrollo Limpio (MDL) bajo el Protocolo de Kioto. Sin embargo, una pregunta clave es cómo funcionará este mecanismo en un mundo de INDCs, donde los países en desarrollo (como posibles anfitriones) también tienen sus bases de referencia y/o niveles de referencia acordados" ${ }^{50}$. Quizás mediante este mecanismo se reconduzca el futuro del MDL.

\subsection{El principio de equidad}

En el mencionado artículo 4 del Acuerdo, al final, hay una referencia a "sobre la base de la equidad y en el contexto del desarrollo sostenible y de los esfuerzos por erradicar la pobreza", y se agrega el principio de equidad intergeneracional al contexto de este instrumento internacional.

La noción de equidad surge con frecuencia en el Acuerdo de París; en el Preámbulo del Tratado hay dos referencias a la equidad y a la equidad intergeneracional, que también aparecen en el Preámbulo de la decisión de adopción ${ }^{51}$. En las disposiciones operacionales del Acuerdo de París se señala que las Partes deben proteger el clima sobre la base de la equidad y el principio de responsabilidades comunes pero diferenciadas (arts. 2 y 4). Es interesante la manera como se conecta la equidad con la erradicación de la pobreza.

El principio de equidad intergeneracional se explica en relación con las generaciones que no se encuentran representadas en el proceso de toma de decisiones de hoy y que son habitualmente ignoradas en sus preferencias, con lo que se eliminan los potenciales intercambios entre las generaciones

49 Artículo 6: “... El mecanismo será supervisado por un órgano que designará la Conferencia de las Partes en calidad de reunión de las Partes en el presente Acuerdo, y tendrá por objeto: a) Promover la mitigación de las emisiones de gases de efecto invernadero, fomentando al mismo tiempo el desarrollo sostenible; b) Incentivar y facilitar la participación, en la mitigación de las emisiones de gases de efecto invernadero, de las entidades públicas y privadas que cuenten con la autorización de las Partes; c) Contribuir a la reducción de los niveles de emisión en las Partes de acogida, que se beneficiarán de actividades de mitigación por las que se generarán reducciones de las emisiones que podrá utilizar también otra Parte para cumplir con su contribución determinada a nivel nacional; y d) Producir una mitigación global de las emisiones mundiales".

50 Traducción libre. Cordonier Segger. Advancing the Paris Agreement on Climate Change for Sustainable Development, cit., 206.

51 Párrafo 7: "Reconociendo también que el cambio climático es un problema común de la humanidad $[\ldots]$ y la equidad intergeneracional". 
presentes y las futuras. Es así como la generación actual puede beneficiarse de la utilización de los recursos naturales a expensas de las generaciones futuras.

La implicación del principio es que requiere que cada generación use y desarrolle su patrimonio natural y cultural de manera tal que no se pueda transferir a las futuras generaciones en condiciones peores de las que fue recibido, cuidando en especial de los recursos naturales ${ }^{52}$.

Una de las aplicaciones prácticas del principio desde la perspectiva nacional pasa, a nuestro juicio, por actualizar los regímenes de recursos naturales lo más pronto posible, pues se verán directamente afectados por los impactos del cambio climático. En general, en los países latinoamericanos se observa que muchas de las regulaciones sobre la materia fueron emitidas en la década 1970 y 1980 , cuando el cambio climático no era parte de las preocupaciones ambientales.

La implementación doméstica de este principio exigirá poner especial cuidado a que las medidas de adaptación y mitigación que se adopten respeten la equidad climática de las cargas que se imponen, dado que en los hechos estas acciones implicarán restricciones de derechos fundamentales; por esta razón, en el caso de Chile aconsejamos la adopción de una ley de cambio climático como lo más apropiado ${ }^{53}$.

En definitiva, concordamos con Redgwell ${ }^{54}$ cuando manifiesta que la equidad intergeneracional es un principio guía que sirve para la aplicación sustantiva de las normas de los tratados climáticos, y que sus alcances van a depender de los próximos cruciales pasos en que evolucione el régimen climático. Otro aporte de la autora es la afirmación en el sentido de que el principio podrá atender a las circunstancias nacionales que muchos instrumentos jurídicos incluyen y que tienen directa relación con las propias capacidades de los Estados.

\subsection{El principio de transparencia}

Es destacable del Acuerdo de París el énfasis en el principio de transparencia, que significa claridad, en las comunicaciones al sistema internacional. Hay varias normas que se ocupan del tema, y a continuación mencionamos

52 En general, los problemas de equidad entre generaciones surgen del agotamiento de los recursos no renovables y de la eliminación de los renovables, del deterioro de la calidad de los recursos, de la carencia de tecnología y de recursos sustitutos.

53 Chile se encuentra en proceso de elaboración del anteproyecto de ley marco, que se someterá a consulta pública a mediados del año 2019, según informa el Ministerio del Medio Ambiente. Véase: http://portal.mma.gob.cl/cambio-climatico/dialogos-ciudadanos-para-laelaboracion-del-anteproyecto-de-ley-marco-de-cambio-climatico/ [Consultado el 8 de enero de 2019].

54 Redgwell, C. Intra- and Inter-Generational Equity. En Carlarne, C. P.; Gray, K. R. y TARASOFSKy, R. G. (eds.), The Oxford Handbook of International Climate Change Law. UK: Oxford University Press, 2016, 185-201, 185 y 186. 
algunas evidencias de la transparencia que van configurando este principio en el Acuerdo.

Las contribuciones determinadas a nivel nacional (NDC) que comuniquen las Partes se inscribirán en un registro público que llevará la Secretaría, y al rendir cuentas de las emisiones y la absorción antropógenas correspondientes a sus contribuciones, las Partes deberán promover la integridad ambiental, la transparencia, la exactitud, la exhaustividad, la comparabilidad y la coherencia, así como velar por que se evite el doble cómputo, de conformidad con las orientaciones que apruebe la Conferencia de las Partes. Se prevé una metodología que los Estados siguen en sus comunicaciones (art. 4 nums. 12 у 13).

Luego se retoman estas ideas, mencionando que se establece un marco de transparencia reforzado para las medidas, con el fin de fomentar la confianza mutua y de promover la aplicación efectiva, considerando con flexibilidad las diferentes capacidades de las Partes y sobre la base de la experiencia colectiva (art. 13 num. 1). En directa conexión con la transparencia, se habla del "marco de transparencia" como la base del financiamiento.

El Acuerdo no solo focaliza la transparencia desde las Partes, sino que va por más, al establecer el Balance Mundial, como un mecanismo colectivo que se realiza cada cinco años y que hará la Conferencia de las Partes, para determinar el avance colectivo en el cumplimiento de su propósito y de sus objetivos a largo plazo; y lo hará de manera global y facilitadora, examinando la mitigación, la adaptación, los medios de aplicación y el apoyo, y a la luz de la equidad y de la mejor información científica disponible. El primer Balance Mundial tiene fecha: el año 2023 (art. 14). Vemos entonces que claramente parte de la evaluación global se referirá tanto a la adaptación como a la clásica mitigación.

Una de las consecuencias del principio de transparencia de cara al ámbito doméstico es la mejora expresa de la participación ciudadana, dispuesta por el artículo 12 que se refiere al acceso a la información, a la educación y formación, a la sensibilización y participación del público y al acceso a la información sobre cambio climático ${ }^{55}$.

Esta mención expresa en el Acuerdo de París se concentra en una de las funciones que la transparencia tiene en la gobernanza y en el derecho internacional, al decir de Peters ${ }^{56}$. La autora indica que es palpable la demanda

55 Téngase presente que en nuestro continente se encuentra en proceso de aprobación el Acuerdo Regional sobre el Acceso a la Información, la Participación Pública y el Acceso a la Justicia en Asuntos Ambientales, desde del 4 de marzo de 2018, cuando fue adoptado por América Latina y el Caribe en Escazú (Costa Rica). Véase: https://repositorio.cepal.org/bitstream/ handle/11362/43595/1/S1800429_es.pdf [Consultado el 16 de febrero de 2019].

56 Véase Peters, A. The Transparency of Global Governance. En Pazartzis, F.; Gavouneli, M. A.; Gourgourinis, A. y Papadaki, M. (eds.), Reconceptualising the Rule of Law in Global Governance, Resources, Investment \& Trade. Oxford: Hart, 2016, cap. 1. 
de mayor transparencia en las instituciones y en los procedimientos en los principales campos del derecho internacional, en la voz de actores civiles, dentro de los Estados y en las propias organizaciones, tendencia a la que se ha sumado el Acuerdo.

Este principio de transparencia se considera una de las grandes fortalezas del régimen climático. Si ponemos de ejemplo a Chile, la Tercera Comunicación a la Convención Climática fue emitida en noviembre de 2016 y cuenta con 505 páginas de muy nutrida información sobre todos los aspectos del cambio climático y las medidas de mitigación y adaptación que están siendo diagnosticadas, implementadas y en proceso de preparación ${ }^{57}$. Asimismo, si vemos la trayectoria chilena en la creación de la arquitectura para afrontar el cambio climático, advertimos que cuenta con financiamiento internacional, y esto se ha podido alcanzar con institucionalidad y con instrumentos de gestión ambiental que se han ido creando de manera sostenida desde el año 2006 para, justamente, contar con este financiamiento ${ }^{58}$.

Pensamos que la transparencia y su rol en la creación de confianza mutua dentro del régimen se irá construyendo sobre la base de las comunicaciones nacionales de los GEI y sumideros que los Estados se han comprometido y envían desde la Convención Marco, junto con los informes bienales y de actualización, de modo de someter esta parte de sus políticas públicas al escrutinio internacional. Además, todas las Partes realizarán un Balance Mundial del grado de avance del propio Acuerdo, con lo que está claro que se opta por la transparencia para orientar la acción climática colectiva.

Enmarcado en el ámbito de la transparencia, podemos incluir el Mecanismo Internacional de Varsovia para Pérdidas y Daños (incorporado por el artículo 8). Es positivo que el Acuerdo asuma que el cambio climático genera pérdidas y daños asociados a sus efectos adversos, incluidos los fenómenos meteorológicos extremos; y que el propio sistema climático obligue a todos los Estados a contar con sistemas de alerta temprana y a prepararse para situaciones de emergencia, e incluso abre la posibilidad de que estos sistemas preventivos funcionen mediante la coordinación de varios Estados miembros del Acuerdo (p. ej., por regiones). Hay un reconocimiento del riesgo que el cambio climático comporta para los Estados, y también de que la resiliencia es parte de lo que deben enfrentar juntos.

La planificación de las respuestas ante contingencias y desastres a nivel nacional, causados por el cambio climático, es un tema en pleno desarrollo en la doctrina especializada ${ }^{59}$, que muchas veces ubica las medidas dentro

57 Ministerio del Medio Ambiente. Tercera Comunicación Nacional de Chile ante la CMNUCC. 2016. Disponible en: http://portal.mma.gob.cl/wp-content/doc/TCN-2016b1.pdf [Consultado el 11 de febrero de 2019].

58 Para este remitimos a la Tercera Comunicación Nacional, ibíd., 18 a 20 ss.

59 Véase, p. ej., PeEL, J. y Fisher, D. (eds.). The Role of International Environmental Law 
de la adaptación. Este es un tema que exige un mayor compromiso por los países en desarrollo, donde se prevé que habrá mayores consecuencias de los impactos climáticos.

\subsection{El principio de buena gobernanza}

Este acuerdo ambiental de nueva generación asume que la gobernanza que se ocupe del cambio climático deba ser a largo plazo y lo más estable posible. La gobernanza reconoce la importancia de contar con instituciones adecuadas para atender temas ambientales que por su naturaleza requieren de acciones transversales. Además, la buena gobernanza requiere la imposición de objetivos, de toma de decisiones coherentes y el diseño de instituciones para asegurar el desarrollo sostenible, reconociendo la necesidad de nuevos actores para una mejor gobernanza climática ${ }^{60}$.

En este contexto, Cordonier Segger entiende que "la buena gobernanza es esencial en el contexto del Acuerdo de París, particularmente para los enfoques cooperativos que implican el uso de los resultados de mitigación transferidos internacionalmente de las INDCs" $"$.

Los alcances de la buena gobernanza son multinivel para el Acuerdo, que tiene que ver con la propia naturaleza del fenómeno, que van indicando que las acciones a emprender deban ser transversales; además se plantean exigencias de regulación en todos los niveles de gobierno; y por último, porque la entidad del fenómeno no es posible asumirla en un nivel de manera exclusiva.

Lo anterior está contemplado en el artículo 7 numeral 2 que se refiere a la adaptación ${ }^{62}$, como desafío mundial que incumbe a dimensiones locales, subnacionales, nacionales, regionales e internacionales. Advertimos una mayor toma de conciencia de que el régimen climático plantea exigencias de regulación multinivel; a lo que se suma la necesidad de que se propicie un mayor diálogo entre sistemas internacionales. Así este régimen se enmarca en el derecho internacional medioambiental pero también se relaciona con

in Disaster Risk Reduction. Leiden y Boston: Brill y Nijhoff, 2016.

60 Algunas de estas ideas fueron expuesta en LUCAS GARín, A. Nueva institucionalidad ambiental en Chile: un camino hacia la gobernanza ambiental? En NúÑEz LeIVA, J. I. (coord.), Nuevas perspectivas en derecho público. Chile: Universidad Andrés Bello y Librotecnia, 2011, $629-647,630$ ss.

61 CoRdonIER SEgGer. Advancing the Paris Agreement on Climate Change for Sustainable Development, cit., 225; trad. libre.

62 Artículo 7: "2. Las Partes reconocen que la adaptación es un desafío mundial que incumbe a todos, con dimensiones locales, subnacionales, nacionales, regionales e internacionales, y que es un componente fundamental de la respuesta mundial a largo plazo frente al cambio climático y contribuye a esa respuesta, cuyo fin es proteger a las personas, los medios de vida y los ecosistemas, teniendo en cuenta las necesidades urgentes e inmediatas de las Partes que son países en desarrollo particularmente vulnerables a los efectos adversos del cambio climático". 
otras ramas del derecho internacional que merecen evaluaciones en cada caso: piénsese en el sistema multilateral de comercio.

En igual sentido de gobernanza, el Acuerdo de París reconoce la posibilidad de que las medidas de mitigación, en especial, puedan ser tomadas a nivel de organizaciones regionales de integración económica ${ }^{63}$. Hemos concluido por ello que "los Acuerdos Comerciales Regionales pueden hacer mucho por una gobernanza climática que prepare a los Estados Partes para el cambio climático y que concilie comercio y desarrollo sustentable. Aspiramos a que los bloques regionales avancen en este camino"64. En definitiva, el escenario del Acuerdo de París reconoce nuevos actores que deberán participar en las acciones mancomunadas para lograr sus objetivos, entre ellos el sector privado.

Estos compromisos multilaterales exigen de los Estados su inclusión de la lucha contra el cambio climático como un objetivo nacional, que también puede ser regional y local. Hay el reconocimiento, en el Acuerdo de París, a una gobernanza multinivel del cambio climático, como lo mencionamos, y que es necesaria para la fase de implementación que sigue en el futuro.

\subsection{El principio de cooperación}

En varias instancias, el Acuerdo de París ratifica que el principio de cooperación es el que debe guiar las negociaciones y las acciones que se emprendan para la implementación del Acuerdo. Esta validación del principio por este tratado ambiental es una excelente ratificación de que la cooperación continúa siendo la gran herramienta con la que cuenta el derecho ambiental, y que se sigue consolidando como el instrumento que utilizan los Estados para afrontar problemáticas globales que afectan a cada uno de ellos dentro de los límites de su territorio.

Entre las modalidades que asume la cooperación en el Acuerdo podemos mencionar el intercambio de información entre las Partes, la planificación de actividades conjuntas y la coordinación de políticas nacionales, de estudios e investigaciones conjuntos, de los sistemas de financiamiento, etc.

Hay menciones a la "cooperación voluntaria" entre los Estados para la aplicación de sus contribuciones determinadas a nivel nacional para lograr

63 Artículo 4: "16. Las Partes, con inclusión de las organizaciones regionales de integración económica y sus Estados miembros, que hayan llegado a un acuerdo para actuar conjuntamente en lo referente al párrafo 2 del presente artículo, deberán notificar a la Secretaría los términos de ese acuerdo en el momento en que comuniquen sus contribuciones determinadas a nivel nacional". Véase tembién el numeral 18.

64 LuCAS GaRín, A. Cambio climático y acuerdos comerciales regionales. Una mirada desde el Sistema Multilateral de Comercio. Chile: Finis Terrae, 2017, 250. 
sus medidas de mitigación y adaptación ${ }^{65}$. Y también se habla de "enfoques cooperativos" ${ }^{66}$ para enfrentar estas medidas.

En esta tendencia cooperativa, el Acuerdo reconoce asimismo la necesidad de disponer de enfoques del mercado que sean integrados, holísticos y equilibrados. Una de las aristas de la cooperación debe consistir en conciliar el régimen de cambio climático con el sistema de comercio internacional, como se viene de mencionar. Las interrelaciones entre el comercio y el ambiente han formado parte del derecho internacional, en los últimos años, de modo vigoroso, aunque a primera vista pareciera que los objetivos liberalizadores del derecho internacional del comercio van en contravía de los objetivos regulatorios del derecho internacional ambiental. Estas tendencias opuestas determinan posibles enfrentamientos y por ello requieren acomodamientos, por lo que es deseable que se sumen más voces dispuestas a tender puentes entre estos dos campos de acción.

En suma, la etapa actual del régimen climático requiere de una cooperación compleja que pasa ante todo por el establecimiento de estándares de manera común, así como por compartir las informaciones que se van generando en torno a la aplicación de esos estándares. Su implementación, pensamos, puede llevar la cooperación a límites aún no alcanzados en otros regímenes internacionales.

\subsection{El principio precautorio}

El cambio climático requiere un enfoque precautorio ${ }^{67}$, pues la propia naturaleza del fenómeno que brevemente reseñamos en el punto 2 nos indica que si bien ya son apreciables sus impactos, tener una idea acabada de qué significará para la humanidad el cambio climático resulta difícil; de allí la tarea continuada del IPCC que se encuentra preparando su sexto reporte para el año $2022^{[68]}$. Además, el cambio climático está llamado a ser un tema que

65 Artículo 6: "1. Las Partes reconocen que algunas Partes podrán optar por cooperar voluntariamente en la aplicación de sus contribuciones determinadas a nivel nacional para lograr una mayor ambición en sus medidas de mitigación y adaptación y promover el desarrollo sostenible y la integridad ambiental".

66 Artículo 6: "2. Cuando participen voluntariamente en enfoques cooperativos que entrañen el uso de resultados de mitigación de transferencia internacional para cumplir con las contribuciones determinadas a nivel nacional, las Partes deberán promover el desarrollo sostenible y garantizar la integridad ambiental y la transparencia, también en la gobernanza, y aplicar una contabilidad robusta que asegure...".

67 Hablamos del principio 15 de la Declaración de Río: "Con el fin de proteger el medio ambiente, los Estados deberán aplicar ampliamente el criterio de precaución conforme a sus capacidades. Cuando haya peligro de daño grave o irreversible, la falta de certeza científica absoluta no deberá utilizarse como razón para postergar la adopción de medidas eficaces en función de los costos para impedir la degradación del medio ambiente".

68 La COP 21 ha invitado al IPCC a proporcionar un informe especial en 2018 sobre las repercusiones del calentamiento global de $1,5^{\circ} \mathrm{C}$ por encima de los niveles preindustriales y las 
penetre todas las áreas de toma de decisiones sociales, desde la energía hasta la agricultura, desde las migraciones hasta las decisiones personales, por lo que las perspectivas legales y políticas son diversas, como señala Bergkamp ${ }^{69}$.

En el artículo 7 numeral 5, referido a las acciones de adaptación ${ }^{70}$, se menciona que ellas debieran inspirarse en la "mejor información científica disponible". La pregunta que surge es si de ello es posible derivar que con esta mención el principio precautorio se halla presente en el Acuerdo de $\mathrm{Pa}$ rís. Creemos que la respuesta es afirmativa. Veamos qué piensa la doctrina al respecto.

Hanekamp y Bergkamp ${ }^{71}$ explican que hay una asunción del principio precautorio con la carga de la prueba del cambio climático, y desde la Convención Marco que incluyeron una suposición por defecto del cambio climático causado por el hombre debido a las emisiones antropógenas de gases de efecto invernadero en las definiciones que fueron codificadas. Y señalan que esto se ve reforzado por el Acuerdo de París. Esto, para los autores, genera un problema, dado que en el marco del Acuerdo la "mejor ciencia disponible" solo puede entenderse como una investigación que sea coherente con la redacción del Acuerdo. Por lo tanto, no hay necesidad de definir lo que significa "la mejor ciencia disponible". Así, la investigación en competencia en el campo del cambio climático tiene pocas posibilidades de desarrollarse, ya que es difícil obtener financiación adecuada.

A diferencia de los autores en cita, pensamos que en la ciencia siempre hay espacio para el disenso, y que a lo largo del tratamiento del cambio climático como una problemática internacional ha habido muchas opiniones distintas. Posiblemente hoy día la mejor información científica posible sea la que brinda el IPCC, por las razones que expusimos. Incluso el alejamiento de Estados Unidos del Acuerdo puede generar otras investigaciones científicas financiada por ese país, que en los albores de la investigación de cambio climático en la década 1970 y 1980 tuvo un rol importante.

rutas mundiales relacionadas con las emisiones de gases de efecto invernadero. El Special Report on the Impacts of Global Warming of $1.5^{\circ} \mathrm{C}$ fue publicado el 8 de octubre de 2018. Disponible en: https://www.ipcc.ch/sr15/ [Consultado 15 de febrero de 2019].

69 BERGKAMP, L. The Paris Agreement on Climate Change: A Risk Regulation Perspective. En Eur. J. Risk Reg. Vol. 7, 35-41, 41.

70 Artículo 7: "5. Las Partes reconocen que la labor de adaptación debería llevarse a cabo mediante un enfoque que deje el control en manos de los países, responda a las cuestiones de género y sea participativo y del todo transparente, tomando en consideración a los grupos, comunidades y ecosistemas vulnerables, y que dicha labor debería basarse e inspirarse en la mejor información científica disponible y, cuando corresponda, en los conocimientos tradicionales, los conocimientos de los pueblos indígenas y los sistemas de conocimientos locales, con miras a integrar la adaptación en las políticas y medidas socioeconómicas y ambientales pertinentes, cuando sea el caso".

71 Hanekamp, J. C. y Bergkamp, L. The "Best Available Science" and the Paris Agreement on Climate Change. En Eur. J. Risk Reg. Vol. 7, 42, 2016, 42-48, 43; trad. libre. 
Algunos científicos manifiestan que el calentamiento global exige avanzar en investigación, por ejemplo en el Manejo de la Radiación Solar (Solar Radiation Management, SRM), que es un tipo de "geoingeniería" propuesta que compensaría la acumulación de GEI al reflejar la luz del sol antes de que calentara la atmósfera. Es una perspectiva que, según el Premio Nobel de Economía Tom Schelling, requiere ser discutida para colaborar con el equilibrio del clima ${ }^{72}$.

El IPCC, desde el Quinto Reporte de finales de 2014, que es el último publicado, ha seguido ratificando las informaciones que señalan que el fenómeno se debe a las emisiones de GEI. Es muy difícil negar que estas informaciones seguirán siendo la base de la acción mancomunada de las Partes, que debe profundizarse a partir del Acuerdo de París.

\section{OTROS TEMAS DESTACABLES DEL ACUERDO DE PARÍS}

Resulta interesante que el Acuerdo de París incluya cuestiones de género, que en el artículo 7 numeral 5 la relacionan con la adaptación; y que cuando se refiere al "fomento de capacidades" también incorpore la mirada de género ${ }^{73}$. Es la primera inclusión expresa y formal en un tratado del régimen climático de esta visión que hermana las graves amenazas que la problemática climática está generando y la visión de género.

En el marco de las largas negociaciones climáticas, las cuestiones de género se han visto incluidas en la preocupación porque las mujeres estuvieran representadas en las negociaciones y en las delegaciones de las Partes, como también en un avance en el enfoque de género en las políticas climáticas ${ }^{74}$.

De manera expresa, el Preámbulo incluye un considerando que indica:

Reconociendo que el cambio climático es un problema de toda la humanidad y que, al adoptar medidas para hacerle frente, las Partes deberían respetar, promover y tener en cuenta sus respectivas obligaciones relativas a los derechos humanos,

72 Schelling, T. Norms, conventions, and institutions to cope with climate change. En Hahn, R. W. y Ulp, A. (eds.), Climate Change and Common Sense. Essays in honor of Tom Schelling. UK: Oxford University Press, 2012, 20-26, 20 ss. Schelling falleció en diciembre de 2016; había ganado el Premio Nobel en 2005 por la aplicación de la teoría de juegos en diversos ámbitos. Este intelectual norteamericano se ocupó durante décadas del cambio climático.

73 Artículo 7: "5. Las Partes reconocen que la labor de adaptación debería llevarse a cabo mediante un enfoque que deje el control en manos de los países, responda a las cuestiones de género". Artículo 11 numeral 2, in fine: "El fomento de la capacidad debería guiarse por las lecciones aprendidas, también en las actividades en esta esfera realizadas en el marco de la Convención, y debería ser un proceso eficaz e iterativo, que sea participativo y transversal y que responda a las cuestiones de género".

74 En la web oficial de la United Nations Climate Change se expresa que desde 2012 las Partes de la comnuc han considerado a ‘Género y cambio climático' parte de la agenda. Disponible en: http://unfccc.int/gender_and_climate_change/items/7516.php [Consultado el 15 de febrero de 2019]. 
el derecho a la salud, los derechos de los pueblos indígenas, las comunidades locales, los migrantes, los niños, las personas con discapacidad y las personas en situaciones vulnerables y el derecho al desarrollo, así como la igualdad de género, el empoderamiento de la mujer y la equidad intergeneracional.

Otro grupo vulnerable mencionado en el Preámbulo son los niños, referencia que se ha visto acompañada por el Informe del Relator Especial John Knox sobre la relación entre los derechos del niño y la protección del medio ambiente $^{75}$; la interrelación entre la Convención de los Derechos del Niño y el régimen climático plantea desafíos concretos que ojalá sean atendidos tanto en el propio sistema internacional como en las políticas domésticas.

El Preámbulo indica que los Estados deben atender al cambio climático pero teniendo en cuenta sus respectivas obligaciones relativas a los derechos humanos. Esto nos lleva a otro de los temas del Acuerdo, precisamente, el de los derechos humanos.

Según Bodansky, "la disposición no amplía las obligaciones de los países en materia de derechos humanos; más bien, se refiere a las obligaciones 'respectivas' de las partes. Queda por ver si esta referencia pasajera a los derechos humanos proporciona una base sobre la cual construir"76.

Además, esta tendencia a relacionar derechos humanos y medio ambiente se ha visto fortalecida en nuestro continente con la Opinión Consultiva de la Corte Interamericana de Derechos Humanos sobre Medio Ambiente y Derechos Humanos ${ }^{77}$ que de manera sistemática y profunda aborda esta conexión, poniendo a la largo del texto justamente al cambio climático como ejemplo de fenómeno que puede afectar los derechos.

Consideramos que es relevante esta conexión expresa que realiza el Acuerdo, que se suma a todas las voces que en los últimos años han señalado que el cambio climático implicará violaciones de derechos humanos. Asimismo, se muestra una intención firme del Acuerdo de superar la fragmentación del derecho internacional e interrelacionarse con otros regímenes internacionales, con una mirada más transversal de los regímenes internacionales.

75 Informe del Relator Especial Derechos del Niño y el Medio Ambiente. Consejo de Derechos Humanos. A/HRC/37/58. Versión para niños disponible en: https://www.ohchr.org/ Documents/Issues/Environment/SREnvironment/unsREnvir_Spanish.pdf [Consultado el 15 de febrero de 2019].

76 Bodansky, D. The Paris Climate Change Agreement: a new hope? En The American Journal of International Law. Vol. 110, 2, 2016, 313; traducción libre. El autor cuenta que la esperanza de las ONGs en la COP 21 era la inclusión de una norma expresa sobre derechos humanos en la parte operativa del Acuerdo.

77 El 15 de noviembre de 2017 la Corte Interamericana de Derechos Humanos dictó la Opinión Consultiva OC-23/17 sobre "Medio Ambiente y Derechos Humanos", notificada el 7 de febrero de 2018. 


\section{CONCLUSIONES}

Para cerrar este itinerario por el Acuerdo de París quisiéramos destacar algunas consecuencias. Pensamos que la relevancia del Acuerdo de París es mucha, pues implica una renovación del ámbito multilateral de negociaciones de los Estados; pareciera que el último gran tratado multilateral fue el Estatuto de Roma para la creación de la Corte Penal Internacional en 1998; y si seguimos esta línea, el Acuerdo de París permite recuperar la esperanza en el ámbito multilateral.

Superar la imagen negativa y la mala prensa que generó el Protocolo de Kioto es un desafío que tienen los Estados que han decidido permanecer en el Acuerdo de París y en el régimen internacional. Esto en un escenario de política internacional con la renuncia de Estados Unidos al Acuerdo y con China más activa en el régimen, como los grandes emisores, junto a una Unión Europea decidida a seguir siendo líder en la lucha climática.

El Acuerdo plasma un consenso que podría llamarse de "mínimo denominador común" porque no existió una alternativa viable en las negociaciones para alcanzar un consenso mayor, de manera que este consenso representa solo lo que es políticamente factible, no lo que la ciencia y la tecnología consideran necesario para la lucha contra el cambio climático ${ }^{78}$.

Las cuestiones legales y de política relacionadas con el cambio climático son diversas, y también lo son las perspectivas sobre los problemas quizás desde el Acuerdo de París estas cuestiones conexas parecen más evidentes, por lo pronto una tendencia a interrelacionar el régimen de cambio climático con otros regímenes, pueda colaborar a superar la fragmentación, y sumar una mayor perspectiva de derechos humanos es una tarea por hacer para el Acuerdo y de todo el régimen internacional.

La actual etapa del régimen de cambio climático, centrada en la implementación, requiere un desarrollo en múltiples aspectos, y los principios o conceptos básicos cuyo tratamiento abordamos en este trabajo permitirán ir delineando las medidas que deben tomarse en esta etapa, tanto a nivel doméstico como en el propio régimen internacional.

Este recorrido por el Acuerdo de París desde los principios ambientales nos da una buena impresión y nos lleva a confiar en que podría haber un cambio de enfoque en el tratamiento multilateral del cambio climático. Desde nuestro análisis, ese cambio de enfoque pasará principalmente por la acción climática mancomunada, sumada a una mayor transparencia, a la equidad, a la buena gobernanza, a la precaución y, con toda certeza, a una mayor cooperación.

78 Véase Boyle, A. y Ghaleigh, N. S. Climate Change and International Law beyond the unfCCc. En Carlarne, C. P.; Gray, K. R. y Tarasofsky, R. G. (eds.), The Oxford Handbook of International Climate Change Law. UK: Oxford University Press, 2016, 26-54, 53. 
La atención a estos principios ciertamente no resuelve el cambio climático, pero es un punto de partida para que la comunidad internacional pase a ser más garante de las medidas a nivel nacional. Además de que aquellos resultan fundamentales para la aplicación con éxito del Acuerdo de París.

El debate en torno al cambio climático abre un espacio de reflexión no solo para mejorar las regulaciones ambientales y climáticas que son necesarias, sino también para ocuparse del desarrollo. Por ello, el Acuerdo revitaliza el desarrollo sostenible como un objetivo global.

El repaso de los principios permite confirmar que el cambio climático es un verdadero problema retorcido o "wicked problem". Esperamos que nuestros Estados puedan considerar que el cambio climático constituye un tema relevante y sigan profundizando su tratamiento en la agenda pública, aprobando los instrumentos jurídicos de conformidad con los principios ambientales del Acuerdo de París.

\section{REFERENCIAS}

Abreu, L. Miradas del desarrollo sustentable. En González Acosta, G. Derecho ambiental y desarrollo sustentable. Buenos Aires: Ediciones Jurídicas, 2015, 23-45.

Arístegui, J. P. Evolución del principio "Responsabilidades comunes pero diferenciadas" en el régimen internacional del cambio climático. En Anuario de Derecho Público. 2012, 585-611.

BergKamp, L. The Paris Agreement on Climate Change: A risk regulation perspective. En Eur. J. Risk Reg. Vol. 7, 2016, 35-41.

Beyerlin, U. Sustainable development. En Wolfrum, R. (ed.), Max Planck Encyclopedia of Public International Law, Oxford University Press, 2013. Disponible en: www. mpepil.com [Consultado el 16 de octubre de 2015).

Bodansky, D. The Paris Climate Change Agreement: A new hope? En The American Journal of International Law. Vol. 110, 2, 2016, 288-319.

Borràs Pentinat, S. Los regímenes internacionales de protección del medio ambiente. Valencia, Tirant lo Blanch, 2011.

Boyle, A. y Ghaleigh N. S. Climate change and international law beyond the UNFCCC. En Carlarne, C. P.; Gray, K. R. y Tarasofsky, R. G. (eds.), The Oxford Handbook of International Climate Change Law. UK: Oxford University Press, 2016, 26-54.

CAsola, L. y Freier, A. El nexo entre cambio climático y energía renovable en el Mercosur. Un análisis comparativo de las legislaciones de Argentina y Brasil. En Derecho del Estado, Universidad Externado de Colombia, N. ${ }^{\circ} 40,2018,153-179$.

Corendea, C. Hybrid legal approaches towards climate change: Concepts, mechanisms and implementation. En Annual Survey of Int'l \& Comp. Law. 21, 2016, 29-41.

Cordonier Segger, M.-C. Advancing the Paris Agreement on Climate Change for Sustainable Development. En Cambridge J. Int'l \& Comp. L. Vol. 5, n. . 2, 2016, 202-237. 
Cottier, T.; Aerni, P.; Karapinar, B.; Matteotti, S.; De Sépibus, J. y Shingal, A. The Principle of Common Concern and Climate Change. En Archiv des Völkerrechts. T. 52, 2014, 293-324.

D'Aspremont, J. Towards a new theory of sources in International Law. En OrFord, A. y Hoffmann, F. (eds.), The Oxford Handbook of the Theory of International Law. United States of America: Oxford University Press, 2016, 545-563.

Dessler, A. Introduction to Modern Climate Change, 2. ${ }^{\text {a }}$ ed. UK: Cambridge University Press, 2016.

Drnas de Clément, Z. Cambio climático: algunas consideraciones de carácter introductorio. En Drnas de Clément, Z. (dir.), Cuaderno de Derecho Ambiental Número 1, Cambio Climático. Córdoba: Academia Nacional de Derecho y Ciencias Sociales de Córdoba, 2009, 9-19.

Fankhauser; S. y McDermott, T. K. J. Climate-resilent development: An introduction. En Fankhauser, S. y McDermott, T. (eds.), The Economics of Climate-Resilient Development. UK: Edward Elgar, 2016.

GHERING, M. La transición legal a una economía verde. En Revista de Derecho Ambiental. IV, n. ${ }^{\circ}$ 6, 2016, 8-43.

Hanekamp, J. C. y Bergkamp, L. The "Best Available Science" and the Paris Agreement on Climate Change. En Eur. J. Risk Reg. Vol. 7, 42, 2016, 42-48.

Hestermeyer, H. Reality or Aspiration? Solidarity in International Environmental and World Trade Law. En H. Hestermeyer et al. (eds.), Coexistence, Cooperation and Solidarity: Liber Amicorum Rüdiger Wolfrum. Vol. 1. Martinus Nijhoff, 2012, 45-63.

Grupo Intergubernamental de Expertos sobre el Cambio Climático. Cambio Climático. Informe de Síntesis 2014. Suiza: IPCC y Organización Meteorológica Mundial (омM), 2015.

LuCAS GARín, A. Cambio climático y acuerdos comerciales regionales. Una mirada desde el Sistema Multilateral de Comercio. Chile: Finis Terrae, 2017.

Lucas Garín, A. Nueva institucionalidad ambiental en Chile: un camino hacia la gobernanza ambiental? En Núñez LeIVA, J. I. (coord.), Nuevas perspectivas en derecho público. Chile: Universidad Andrés Bello y Librotecnia, 2011, 629-647.

Mayer, B. The relevance of the No-Harm Principle to climate change law and politics. En Asia-Pacific Journal of Environmental Law. Vol. 19, 2016, 79-104.

Ministerio del Medio Ambiente Tercera Comunicación Nacional de Chile ante la CMnUCC. 2016. Disponible en: http://portal.mma.gob.cl/wp-content/doc/TCN-2016b1.pdf [Consultado el 11 de febrero de 2019.

Peters, A. The transparency of global governance. En Pazartzis, F.; Gavouneli, M. A.; Gourgourinis, A. y Papadaki, M. (eds.), Reconceptualising the Rule of Law in Global Governance, Resources, Investment \& Trade. Oxford: Hart, 2016. 
Redgwell, C. Intra- and inter-generational equity. En Carlarne, C. P.; Gray, K. R. y TARAsofsky, R. G. (eds.), The Oxford Handbook of International Climate Change Law. UK: Oxford University Press, 2016, 185-201.

Rittel, H. W. J. y Webber, M. M. Dilemmas in a general theory of planning. En Policy Sciences. Vol. 4, n. ${ }^{\circ}$ 2, 1973, 155-169.

Robador Moreno, A. Cambios climáticos. Madrid: Los libros de la catarata, 2015.

Robinson, N.; XI, W.; Harmon, L. y Wegmueller, S. Dictionary of Environmental and Climate Change Law. UK: Edward Elgar, 2013.

Romanin JACUR, F. El Acuerdo de París sobre cambio climático: un tratado con muchos matices. En Jiménez Guanipa, H. y Tous Chimá, J. (eds.), Cambio climático, energía y derechos humanos: desafíos y perspectivas. Bogotá: Universidad del Norte y Fundación Heinrich Böll, 2017, 22-32.

Rowell, A. y van Zeben, J. A new status quo? The psychological impact of the Paris Agreement on Climate Change. En Eur. J. Risk Reg. Vol. 7, 2016, 49-53.

Sarasíbar Iriarte, M. Régimen jurídico del cambio climático. España: Lex Nova, 2006.

Schelling, T. Norms, conventions, and institutions to cope with climate change. En HaHN, R. W. y Ulp, A. (eds.), Climate Change and Common Sense. Essays in Honor of Tom Schelling, Great Britain, Oxford University Press, 2012, 20-26.

Schiele, S. Evolution of International Environmental Regimes. The Case of Climate Change. UK: Cambridge University Press, 2014.

VAlencia Restrepo, H. Introducción a una nomoárquica ambiental. En DrNas de Clément, Z. (coord.), Estudios de derecho internacional en homenaje al profesor J. Ernesto Rey Caro. T. 1. Córdoba: Marcos Lerner, 2002, 105-137.

Viñuales, J. E. The Paris Agreement on Climate Change: Less is more. En German Yearbook of International Law. 2017, 11-45.

Wolfrum, R. Sources of International Law. En The Max Planck Encyclopedia of Public International Law. UK: Oxford University Press, 2012, 299-313.

\section{Normativa}

Acuerdo de París, adoptado en la 21. a sesión de la Conferencia de las Partes (Cop) del 30 de noviembre al 12 de diciembre de 2015 en París, Francia. Vigente desde el 4 de noviembre de 2016.

Convención Marco de Naciones Unidas sobre el Cambio Climático, adoptada en Nueva York el 9 de mayo de 1992. Vigente desde el 21 de marzo de 1994.

Declaración de Estocolmo sobre el Medio Ambiente Humano, adoptada en la Conferencia de las Naciones Unidas sobre el Medio Ambiente Humano, 16 de junio de 1972. 
Declaración de Río sobre el Medio Ambiente y el Desarrollo, adoptada en la Conferencia de las Naciones Unidas sobre el Medio Ambiente y el Desarrollo, Río de Janeiro, del 3 al 14 de junio de 1992.

Protocolo de Kioto, adoptado en la 3. a sesión de la Conferencia de las Partes (COP) el 11 de diciembre de 1997 en Kioto, Japón. Vigente desde el 16 de febrero de 2005. 